\title{
Vegetative Compatibility Groups in Colletotrichum coccodes, the Causal Agent of Black Dot on Potato
}

\author{
N. Nitzan, M. Hazanovsky, M. Tal, and L. Tsror (Lahkim)
}

First and third authors: Department of Life Sciences, Ben Gurion University, Beer Sheva, Israel; and first, second, and fourth authors:

Department of Plant Pathology, Agricultural Research Organization, Gilat Experiment Station, M.P. Negev, 85280, Israel.

Accepted for publication 8 April 2002.

\begin{abstract}
Nitzan, N., Hazanovsky, M., Tal, M., and Tsror (Lahkim), L. 2002. Vegetative compatibility groups in Colletotrichum coccodes, the causal agent of black dot on potato. Phytopathology 92:827-832.

Black dot of potato, caused by Colletotrichum coccodes, is a disease of growing economic importance, but the degree of genetic diversity and pathogenic differentiation among isolates is unknown. Using nitrate auxotrophic (Nit) mutants, we characterized vegetative compatibility groups (VCG) diversity for $C$. coccodes for 110 isolates originating from Israel, The Netherlands, and France. We recovered frequencies of nit 1 and NitM mutant classes at 38.5 and $7.2 \%$, respectively, and selected 12 isolates as tester isolates. Using these testers, we defined four multi-

member VCGs at 7.3, 35.5, 20.0, and $10.0 \%$ frequency in this sample. Thirty isolates ( $27.3 \%$ of all tested isolates) could not be assigned to any of the major groups, and showed only self-compatibility. The frequency of recovery of Nit mutant sectors was highest in isolates from VCG4, with 50.9 and $13.6 \%$ recovery for nitl and NitM, respectively. However, we did not detect differences in the frequency of mutant classes among the three countries of origin. In pathogenicity tests, isolates from VCG3 were the most aggressive to potato, as expressed by high stem colonization levels and sclerotia density on root and crown. These results suggest that there is significant VCG diversity in this species and that this VCG diversity may be correlated with pathogenic characteristics or specialization.
\end{abstract}

Black dot on potatoes caused by Colletotrichum coccodes (Wallr.) S. J. Hughes was considered a minor disease worldwide until the early 1990s, when reports from South Africa (9), France (1), and Israel (27) indicated increasing occurrences of the disease and greater impact on potato production. The main factors involved with this increase may be as follows: decreasing tolerance of skin blemishes by growers because tubers are now usually washed before marketing; underestimation of $C$. coccodes disease incidence due to silver lesions being attributed to Helminthosporium solani rather than $C$. coccodes; higher temperatures during the growing seasons that favor $C$. coccodes; and development of black dot as a consequence of fungicide application on seed tubers to control $H$. solani, because most of the active ingredients registered against silver scurf are not efficient against black dot (1).

$C$. coccodes is a soil-, seed-, and airborne pathogen that can attack crops within the family Solanacae, including potato, tomato (5), and pepper (11). Black dot is characterized by the development of small black sclerotia on senescent and dead plant tissues, on decaying roots and stems, and on stolons and daughter tubers, reducing tuber quality and yield $(6,25,27)$. Control strategies for this species include fungicide applications on seed tubers before planting, the use of disease-free seed tubers (9), and soil fumigation $(10,29)$. There have been no reports of resistant cultivars. However, the use of cultivars known to be tolerant to $C$. coccodes may prevent development of the disease in the field $(25,29)$.

Vegetative compatibility refers to the ability of individual fungal strains to undergo mutual hyphal anastomosis and form viable heterokaryons. In asexual species, vegetative compatibility also may serve as a means of genetic exchange (i.e., processes like mitotic recombination). Strains that are vegetatively compatible

Corresponding author: L. Tsror (Lahkim); E-mail address: tsror@bgumail.bgu.ac.il

Publication no. P-2002-0612-01R

(c) 2002 The American Phytopathological Society with one another are described as members of the same vegetative compatibility groups (VCGs) $(13,19,20,22,24)$. When sexual recombination does not occur, isolates within a VCG tend to be more similar than isolates in different VCGs. Isolated VCGs act as genetically isolated lineages that can evolve divergent pathogenicity and vegetative viability traits (20).

Classification of VCGs has been used for studying the genetic structure of populations of plant-pathogenic fungi, including $\mathrm{Fu}$ sarium oxysporum $(16,21,23,24)$, Verticillium $\mathrm{spp}$. $(7,13,24)$, and Colletotrichum spp. (4). In most cases, analysis of VCGs has been based on pairings between complementary nitrate auxotrophic (Nit) mutants of different isolates, selected using chlorate-containing agar. Compatible isolates, whose complementary Nit mutants can form stable heterokaryons, are assigned to the same VCG $(7,13,15)$.

The usefulness of VCGs as a diagnostic tool in plant pathology already has been demonstrated, at least for plant pathogens that do not regularly recombine (20). Due to the disease's increasing economic impact on potato worldwide, studying the structure of populations of $C$. coccodes has become more important. Understanding the diversity within this species may contribute to a better understanding of the epidemiology of the disease and improve its control $(3,13)$.

The hypotheses of the current study were that there is VCG diversity within $C$. coccodes subpopulations and that $C$. coccodes isolates from different VCGs possess different virulence to potato. Our specific objectives were to (i) examine and compare VCG diversity and composition among $C$. coccodes isolates collected from potato in Israel and from imported European seed tubers and (ii) evaluate the aggressiveness of different VCGs to potato, to determine whether there are differences between representatives of these (presumably asexual) VCGs.

\section{MATERIALS AND METHODS}

Collection of isolates. We collected $C$. coccodes isolates from certified potato seed tubers lots imported to Israel from The 
Netherlands and France for the spring seasons of 1999-2000. Israeli isolates were collected from either seed tubers (for the autumn season) or potatoes for consumption, and from infected stems collected from eight different locations.

We isolated $C$. coccodes from surface-sterilized ( $1 \% \mathrm{NaClO}$ for $10 \mathrm{~min}$ ) infected stems or tubers. Sclerotia taken from tuber and stem surface were placed on potato dextrose agar (PDA). Plates were incubated in the dark at $27^{\circ} \mathrm{C}$ for 7 days and allowed to sporulate. Conidia transferred to medium containing $0.2 \%$ sorbose, $15 \%$ agar, and $100 \mathrm{ppm}$ of streptomycin sulfate (SA) were incubated for $24 \mathrm{~h}$ at $27^{\circ} \mathrm{C}$ in the dark. Monoconidial cultures were obtained from each isolate (by micromanipulation) and maintained on czapek dox agar (CDA) (Difco, Le Port de Claix, France) at $6^{\circ} \mathrm{C}(18)$.

Generation and characterization of nit mutants. Nit mutants were generated using techniques described previously $(18,23)$. Water agar chlorate (WAC) medium, containing $2 \%$ agar, $3 \%$ potassium chlorate, and $0.02 \%$ glucose) was used to generate Nit mutants. We placed 10 mycelia plugs $(1 \mathrm{~mm})$ from monoconidial cultures of each isolate on WAC medium and incubated these plates at $27^{\circ} \mathrm{C}$ in the dark. After 21 days of incubation, we transferred growing edges of samples onto petri plates containing CDA medium and allowed them to grow for 5 days. Colonies with a thin mycelium on CDA plates were considered Nit mutants. We carried out partial phenotyping of Nit mutants (nit1/nit3 versus NitM) by placing two mycelial plugs of each isolate on both CDA and CDA amended with $0.02 \%$ hypoxanthine $(4,19)$. Plates were incubated for 5 days at $27^{\circ} \mathrm{C}$ in the dark. Colonies that grew on CDA supplemented with hypoxanthine with a wild-type phenotype, and on CDA with a thin mycelium, were classified as nit1/nit3 mutants. Colonies that grew with a thin mycelium on both media were classified as NitM mutants.

Complementation tests. Complementation between Nit mutants was tested on CDA medium containing sodium nitrate as the nitrogen source. One mycelial block $(1 \mathrm{~mm})$ of NitM and two mycelial blocks of nit 1 were placed $1 \mathrm{~cm}$ apart in a triangular pattern (19). Plates were incubated for 14 days at $27^{\circ} \mathrm{C}$ in the dark. Complementation usually was evident after 10 to 14 days, characterized by prototrophic growth at the contact zone between the two complimentary Nit mutants. During all tests, isolates were represented by the same Nit mutant repetition from their collection (either NitM or nit1).

Plant material. Potato plantlets (C. coccodes-susceptible cvs. Desiree and Mondial) for pathogenicity tests were grown for 5 to

TABLE 1. Complementation tests between nitrate auxotrophic (nit) mutants of Colletotrichum coccodes isolates and the tester isolates ${ }^{\mathrm{x}}$

\begin{tabular}{|c|c|c|c|c|c|c|c|c|c|c|c|c|c|}
\hline \multirow[b]{3}{*}{ 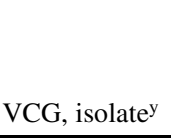 } & \multirow[b]{3}{*}{ Source ${ }^{\mathrm{z}}$} & \multicolumn{12}{|c|}{ nit1/NitM mutants of tester isolates } \\
\hline & & \multicolumn{2}{|c|}{ VCG1 } & \multicolumn{6}{|c|}{ VCG2 } & \multicolumn{2}{|c|}{ VCG3 } & \multicolumn{2}{|c|}{ VCG4 } \\
\hline & & 2 & 16 & 3 & 12 & 13 & 18 & 24 & 53 & 38 & 138 & 46 & 49 \\
\hline \multicolumn{14}{|l|}{ VCG1 } \\
\hline 2 & $\mathrm{~F}$ & + & ++ & - & - & - & - & - & - & - & - & - & - \\
\hline 16 & $\mathrm{~F}$ & ++ & ++ & - & - & - & - & - & - & - & - & - & - \\
\hline 17 & $\mathrm{~F}$ & - & + & - & - & - & - & - & - & - & - & - & - \\
\hline 23 & $\mathrm{~F}$ & - & + & - & - & nt & - & - & - & - & - & - & - \\
\hline 55 & $\mathrm{~N}$ & ++ & - & - & - & - & - & - & - & - & - & - & - \\
\hline 84 & $\mathrm{~N}$ & ++ & + & - & $\mathrm{nt}$ & - & - & - & - & - & - & - & - \\
\hline 160 & I & + & + & - & - & $\mathrm{nt}$ & - & - & - & - & - & - & - \\
\hline 163 & I & ++ & + & - & - & $\mathrm{nt}$ & - & - & - & - & - & - & - \\
\hline \multicolumn{14}{|l|}{ VCG2 } \\
\hline 1 & $\mathrm{~F}$ & - & - & + & + & - & + & - & - & - & - & - & - \\
\hline 3 & $\mathrm{~F}$ & - & - & nt & + & - & + & + & + & - & - & - & - \\
\hline 4 & $\mathrm{~F}$ & - & - & + & ++ & - & ++ & ++ & ++ & - & - & - & - \\
\hline 7 & $\mathrm{~F}$ & - & - & - & + & ++ & - & - & - & - & - & - & - \\
\hline 8 & $\mathrm{~F}$ & - & - & ++ & + & - & + & - & + & $\mathrm{nt}$ & - & - & - \\
\hline 9 & $\mathrm{~F}$ & - & - & ++ & ++ & - & ++ & + & + & - & - & - & - \\
\hline 18 & $\mathrm{~F}$ & - & - & + & + & + & ++ & ++ & ++ & - & - & - & - \\
\hline 19 & $\mathrm{~F}$ & - & - & - & - & + & - & - & - & - & - & - & - \\
\hline 21 & $\mathrm{~F}$ & - & - & + & nt & - & ++ & ++ & ++ & - & - & - & - \\
\hline 22 & $\mathrm{~F}$ & - & - & + & ++ & - & + & + & ++ & - & - & - & - \\
\hline 24 & $\mathrm{~F}$ & - & - & + & + & - & ++ & ++ & ++ & - & - & - & - \\
\hline 32 & $\mathrm{~F}$ & - & - & - & - & ++ & - & - & - & - & - & - & - \\
\hline 33 & $\mathrm{~F}$ & - & - & - & - & ++ & - & + & - & - & - & - & - \\
\hline 34 & $\mathrm{~F}$ & - & - & + & ++ & - & ++ & + & - & - & - & - & - \\
\hline 35 & $\mathrm{~F}$ & - & - & + & + & - & + & - & - & - & - & - & - \\
\hline 12 & $\mathrm{~N}$ & - & - & + & + & - & + & - & ++ & - & - & - & - \\
\hline 37 & $\mathrm{~N}$ & - & - & - & $\mathrm{nt}$ & - & + & ++ & ++ & - & - & - & - \\
\hline 43 & $\mathrm{~N}$ & - & - & - & nt & nt & ++ & - & - & - & - & - & - \\
\hline 44 & $\mathrm{~N}$ & - & - & + & + & - & + & + & ++ & - & - & - & - \\
\hline 53 & $\mathrm{~N}$ & - & - & + & + & - & ++ & ++ & ++ & - & - & - & - \\
\hline 56 & $\mathrm{~N}$ & - & - & - & nt & - & ++ & - & ++ & - & - & - & - \\
\hline 57 & $\mathrm{~N}$ & - & - & - & + & - & - & - & + & - & - & - & - \\
\hline 58 & $\mathrm{~N}$ & - & - & + & ++ & - & + & + & + & - & - & - & - \\
\hline 63 & $\mathrm{~N}$ & - & - & + & + & - & + & + & + & - & - & - & - \\
\hline 65 & $\mathrm{~N}$ & - & - & - & - & - & - & ++ & ++ & - & - & - & - \\
\hline 70 & $\mathrm{~N}$ & - & - & + & - & + & - & - & - & - & - & - & - \\
\hline 76 & $\mathrm{~N}$ & - & - & + & + & - & ++ & + & - & - & - & - & - \\
\hline 78 & $\mathrm{~N}$ & - & - & ++ & nt & - & + & + & + & - & - & - & - \\
\hline 80 & $\mathrm{~N}$ & - & - & + & $\mathrm{nt}$ & - & + & ++ & ++ & - & - & - & - \\
\hline 83 & $\mathrm{~N}$ & - & - & - & $\mathrm{nt}$ & - & ++ & + & + & - & - & - & - \\
\hline 100 & $\mathrm{~N}$ & - & - & ++ & $\mathrm{nt}$ & - & - & - & - & - & - & - & - \\
\hline
\end{tabular}

${ }^{\mathrm{x}}$ Complementation was visually evaluated in three levels: $++=$ dense prototrophic growth,$+=$ sparse prototrophic growth, $-=$ no growth, and nt $=$ not tested.

y $\mathrm{VCG}=$ vegetative compatibility group. Thirty isolates that were incompatible with the tester isolates are not listed.

${ }^{\mathrm{z}} \mathrm{F}=$ France, $\mathrm{N}=$ The Netherlands, and $\mathrm{I}=$ Israel. 
6 weeks (until they were 8 to $10 \mathrm{~cm}$ in height, with three expanded leaves) from sprouts cut from surface-sterilized (0.3\% HCLO) certified seeds, free from $C$. coccodes. The plantlets were grown in a sterile mixture of peat, vermiculite, and perlite $(1: 1: 1, \mathrm{vol} / \mathrm{vol})$ in a growth chamber $\left(20\right.$ to $24^{\circ} \mathrm{C}, 12 \mathrm{~h}$ of light, $\left.100 \mu \mathrm{Em}^{-2} \mathrm{~s}^{-1}\right)$.

Inoculation of plants. Thirty-four $C$. coccodes isolates representing the multimember four VCGs were cultured in $9-\mathrm{cm}$ petri plates containing PDA (Difco) at $27^{\circ} \mathrm{C}$ for 4 to 5 days. A conidial suspension was prepared by collecting the conidia from colonies' surfaces and filtering through four layers of gauze sheet to separate the mycelial and conidial fractions. We estimated the concentration of conidia with a hemocytometer, and adjusted each to a final concentration of $3 \times 10^{5}$ conidia $\mathrm{ml}^{-1}$ with sterile distilled water. Inoculation with the isolates was performed in three separate experiments. In each experiment, we examined different isolates from the four multimember VCGs, except for isolate 138, which demonstrated the highest colonization level in the first experiment, and was used as a reference in the subsequent experiments. Analysis of variance indicated no block effect of splitting up the assays; therefore, data of the three experiments were pooled. We inoculated eight potato plantlets with each of the tested $C$. coccodes isolates by immersing its roots in a conidial suspension for $20 \mathrm{~min}$. Control plants were dipped in sterile distilled water.
The plantlets were transferred to pots filled with a sterile mixture of peat, vermiculite, and perlite (1:1:1, vol/vol). A transparent PVC cylinder enclosed each pot to prevent aerial cross infection. The pots were placed in a growth chamber $\left(20\right.$ to $24^{\circ} \mathrm{C}, 12 \mathrm{~h}$ of light, $100 \mu \mathrm{Em}^{-2} \mathrm{~s}^{-1}$ ) in completely randomized blocks for 40 days. We used this methodology of pathogenicity test previously (28).

Disease evaluation. Disease evaluation was carried out 40 days after inoculation. Density of sclerotia on roots $(5 \mathrm{~cm}$ below stem base) and crown ( $5 \mathrm{~cm}$ above stem base) was evaluated visually on a scale of 0 to 3 , where $0=$ no sclerotia, $1=$ less than $25 \%$ of plant tissue covered with sclerotia, $2=25$ to $50 \%$ cover, and $3=$ above $50 \%$ cover.

Colonization of plant tissue by $C$. coccodes was determined as follows: 10 segments (each $20 \mathrm{~mm}$ long) taken from the stem base of each plant (out of eight plants) were macerated with $5 \mathrm{ml}$ of sterile distilled water in an Ultraturrax blender (Janke Kunkel, Staufen, Germany) for 30 to $60 \mathrm{~s}$ at $4^{\circ} \mathrm{C}$. Duplicate aliquots of $0.1 \mathrm{ml}$ were plated on PDA. After 5 days of incubation in the dark at $27^{\circ} \mathrm{C}$, the colonies were counted.

Statistical analyses. All data were analyzed statistically by SAS Software (SAS Institute Inc., Cary, NC). The general linear model procedure was used to test the effects of inoculation on stem fungal colonization and sclerotia density at the 0.05 level of

TABLE 1. (continued from preceding page)

\begin{tabular}{|c|c|c|c|c|c|c|c|c|c|c|c|c|c|}
\hline \multirow[b]{3}{*}{ VCG, isolate ${ }^{y}$} & \multirow[b]{3}{*}{ Source ${ }^{\mathrm{z}}$} & \multicolumn{12}{|c|}{ nit $1 / \mathrm{NitM}$ mutants of tester isolates } \\
\hline & & \multicolumn{2}{|c|}{ VCG1 } & \multicolumn{6}{|c|}{ VCG2 } & \multicolumn{2}{|c|}{ VCG3 } & \multicolumn{2}{|c|}{ VCG4 } \\
\hline & & 2 & 16 & 3 & 12 & 13 & 18 & 24 & 53 & 38 & 138 & 46 & 49 \\
\hline 101 & $\mathrm{~N}$ & - & - & - & $\mathrm{nt}$ & - & - & - & + & - & - & - & - \\
\hline 13 & I & - & - & - & - & + & + & - & - & - & - & - & - \\
\hline 14 & I & - & - & - & + & ++ & - & - & - & - & - & - & - \\
\hline 157 & I & - & - & - & nt & + & - & + & - & - & - & - & - \\
\hline 165 & I & - & - & - & - & $\mathrm{nt}$ & + & - & - & - & - & - & - \\
\hline 180 & I & - & - & - & + & $\mathrm{nt}$ & + & + & + & - & - & - & - \\
\hline \multicolumn{14}{|l|}{ VCG3 } \\
\hline 11 & $\mathrm{~N}$ & - & - & - & - & - & - & - & - & + & ++ & - & - \\
\hline 28 & $\mathrm{~N}$ & - & - & - & - & - & - & - & - & ++ & ++ & - & - \\
\hline 36 & $\mathrm{~N}$ & - & - & - & - & - & - & - & - & ++ & ++ & - & - \\
\hline 38 & $\mathrm{~N}$ & - & - & - & - & - & - & - & - & ++ & ++ & - & - \\
\hline 77 & $\mathrm{~N}$ & - & - & - & - & - & - & - & - & ++ & ++ & - & - \\
\hline 79 & $\mathrm{~N}$ & - & - & - & - & - & - & - & - & ++ & + & - & - \\
\hline 98 & $\mathrm{~N}$ & - & - & - & - & - & - & - & - & ++ & nt & - & - \\
\hline 135 & I & - & - & - & - & - & - & - & - & ++ & ++ & - & - \\
\hline 137 & I & - & - & - & - & - & - & - & - & ++ & + & - & - \\
\hline 138 & I & - & - & - & - & - & - & - & - & ++ & ++ & - & - \\
\hline 139 & I & - & - & - & - & - & - & - & - & ++ & + & - & - \\
\hline 152 & I & - & - & - & - & - & - & - & - & ++ & ++ & - & - \\
\hline 166 & I & - & - & - & - & $\mathrm{nt}$ & - & - & - & ++ & ++ & - & - \\
\hline 170 & I & - & - & - & - & $\mathrm{nt}$ & - & - & - & ++ & ++ & - & - \\
\hline 171 & I & - & - & - & - & $\mathrm{nt}$ & - & - & - & ++ & ++ & - & - \\
\hline 172 & I & - & - & - & - & nt & - & - & - & ++ & - & - & - \\
\hline 173 & I & - & - & - & - & $\mathrm{nt}$ & - & - & - & ++ & - & - & - \\
\hline 176 & I & - & - & - & - & nt & - & - & - & ++ & - & - & - \\
\hline 105 & $\mathrm{~N}$ & - & - & - & - & - & - & - & - & - & - & ++ & ++ \\
\hline 178 & I & - & - & - & - & $\mathrm{nt}$ & - & - & - & - & - & ++ & ++ \\
\hline ALT-1 & I & - & - & - & - & $\mathrm{nt}$ & - & - & - & - & - & ++ & ++ \\
\hline
\end{tabular}


probability. Averages of sclerotia density and colonization levels first were calculated for each isolate separately; data from isolates of each VCG then were grouped, and the average values for each VCG calculated. Analysis of variance was followed by mean separation using Student-Newman-Keuls or Tukey-Kramer multiple range tests. Data recorded as percentages were arcsin-transformed before analysis. We used Fisher's exact test (2-tail) to compare frequency of VCGs within the isolate source countries, and to compare the frequency of Nit mutant sector types within the VCGs and source countries.

\section{RESULTS}

Collection of isolates. During 1998-2000, we collected 110 isolates of $C$. coccodes from different sources (Table 1). In all, 23 isolates were obtained from certified potato seed tubers originating from France, 51 from the Netherlands, and 36 from plants and tubers from eight locations in Israel. The major cultivars used were Mondial (35\%), Claustar (20\%), and Nicola (9\%).

Generation and characterization of Nit mutants. Nit mutants generated from $C$. coccodes showed a thin and fast-growing mycelium on WAC medium. Recovery from WAC onto CDA was optimal after 21 days of incubation at $27^{\circ} \mathrm{C}$ in the dark. On CDA medium, Nit mutants appeared as thin mycelium with a greenish pigmentation.

The mean frequency of all Nit mutant sectors was $45.6 \%$ (out of 110 isolates by 10 replications) (Table 2). Among the Nit mutants, the nitl class composed $84.3 \%$ of the total number of mutants, while NitM mutants composed $15.7 \%$. The frequency of nit 1 mutants in VCG4 isolates was significantly higher (50.9\%) than in VCG1 and VCG2 isolates (32.5 and 35.4\%, respectively). The frequency of NitM mutants obtained from VCG4 isolates was higher than in VCG2 isolates. No differences in frequency of nit 1 and NitM mutants were observed among the three source countries of the isolates (Table 2).

TABLE 2. Number and frequency of nitrate auxotrophic (nit) mutants within the vegetative compatibility groups (VCGs) and according to country of origin $^{\mathrm{z}}$

\begin{tabular}{lccc}
\hline VCG or source & nit1 mutants & NitM mutants & $\begin{array}{c}\text { Number of } \\
\text { replications }\end{array}$ \\
\hline 1 & $26(32.5 \%) \mathrm{b}$ & $7(8.8 \%) \mathrm{ab}$ & 80 \\
2 & $138(35.6 \%) \mathrm{b}$ & $25(6.1 \%) \mathrm{b}$ & 390 \\
3 & $96(43.6 \%) \mathrm{ab}$ & $16(7.3 \%) \mathrm{ab}$ & 220 \\
4 & $56(50.9 \%) \mathrm{a}$ & $15(13.6 \%) \mathrm{a}$ & 110 \\
Nonassigned & 107 & 16 & 300 \\
Israel & $160(44.4 \%) \mathrm{A}$ & $24(6.7 \%) \mathrm{A}$ & 360 \\
The Netherlands & $192(35.7 \%) \mathrm{A}$ & $40(7.0 \%) \mathrm{A}$ & 510 \\
France & $71(32.4 \%) \mathrm{A}$ & $15(7.7 \%) \mathrm{A}$ & 230 \\
\hline
\end{tabular}

${ }^{\mathrm{z}}$ Number of Nit mutants out of 10 replications for each isolate on water agar chlorate medium. Different letters within columns indicate significant difference between the means within the VCGs (lowercase letters) and the country of origin (capital letters) separately, according to Fisher's exact test (2-tail).

TABLE 3. Number of Colletotrichum coccodes isolates within the vegetative compatibility groups (VCGs) and nonassigned isolates, according the country of origin ${ }^{z}$

\begin{tabular}{lcrrrcr}
\hline & \multicolumn{5}{c}{ VCG } & \\
\cline { 2 - 5 } Source & 1 & 2 & 3 & 4 & Nonassigned & Total \\
\hline Israel & 2 & 7 & 11 & 2 & 14 & $36 \mathrm{a}$ \\
The Netherlands & 2 & 17 & 11 & 9 & 12 & $51 \mathrm{a}$ \\
France & 4 & 15 & 0 & 0 & 4 & $23 \mathrm{~b}$ \\
Total & 8 & 39 & 22 & 11 & 30 & 110 \\
\hline
\end{tabular}

${ }^{\mathrm{z}}$ Multiple comparisons of the distribution of VCGs frequencies among the country of origin, using Fisher's exact test (2-tail), at $P<0.001$. Different letters within a column indicate significant differences.
Complementation tests and selection of VCG testers. During the first stages of research, complementation tests were carried out using Nit mutants generated from 32 arbitrarily selected isolates. Complementary NitM mutants that demonstrated the ability to anastomose with a large number of isolates were chosen as VCG testers (Table 1). Subsequently, all newly collected isolates were tested against these testers to examine VCGs. NitM mutants of new isolates that showed strong complementation with the testers were tested against nitl mutants of isolates from their own VCG, in order to assess their complementation efficiency. New isolates demonstrating an ability to anastomose with a large number of isolates also were used as testers, of either a defined VCG or a new one. Eventually, we selected 12 Nit mutants with an ability to anastomose with a large number of isolates as VCG testers (Table 1). All testers showed an ability to form a stable heterokaryon only with the testers from their own VCG.

Assignment of $C$. coccodes isolates to VCGs. Based on positive complementation reactions with the chosen testers, we identified four multimember VCGs among the 110 isolates (Table 1). However, 30 isolates $(27.3 \%$ ) could not be assigned to any of these four VCGs. All isolates for which we recovered both nit1 and NitM mutants (52 isolates) demonstrated self-compatibility. VCG2 was the largest group and included $35.4 \%$ of all isolates (Table 3); VCG1, VCG3, and VCG4 included 7.3, 20.0, and $10.0 \%$ of all isolates, respectively. Analysis of the frequency of VCG recovery between countries indicated no differences in VCG frequency between isolates originating from Israel and from The Netherlands. However, significant differences were observed in comparing frequencies of VCGs isolates from France and Israel, and frequencies of VCGs isolated from France and The Netherlands (Table 3). We detected isolates from all four VCGs from the Netherlands sample (Table 3), while $23.5 \%$ of that sample could not be assigned to any of the multimember VCGs. We also recovered all four VCGs from Israel, with $38.9 \%$ that could not be assigned to any of the multimember VCGs. We recovered only VCGs 1 and 2 among the isolates from France, with 17.4\% that could not be assigned to a VCG (Table 3).

Pathogenicity tests. We tested 34 isolates representing the four multimember VCGs for their aggressiveness against potato. Isolate 138 (VCG3), which was the most aggressive in the first experiment, was included in all subsequent experiments.

Colonization levels of $C$. coccodes in inoculated plantlets and sclerotia density on roots and crown were significantly highest for VCG3 isolates. Sclerotia density on roots and crown was highest for VCG3 isolates, intermediate for VCG1 and -2 isolates, and lowest for VCG4 isolates (Table 4).

TABLE 4. Pathogenicity of Colletotrichum coccodes isolates to potato from the four multimember vegetative compatibility groups (VCGs) on potato

\begin{tabular}{lcccc}
\hline & & & \multicolumn{2}{c}{ Sclerotia density $(0-3)^{\mathrm{z}}$} \\
\cline { 4 - 5 } VCG & No. tested $^{\mathrm{x}}$ & Colonization $(\mathrm{CFU} / \mathrm{g})^{\mathrm{y}}$ & On roots & On crown \\
\hline 1 & 6 & $1,837 \mathrm{~b}$ & $1.2 \mathrm{~b}$ & $1.3 \mathrm{~b}$ \\
2 & 15 & $1,600 \mathrm{~b}$ & $1.0 \mathrm{~b}$ & $1.2 \mathrm{~b}$ \\
3 & 6 & $3,990 \mathrm{a}$ & $1.7 \mathrm{a}$ & $1.8 \mathrm{a}$ \\
4 & 7 & $1,854 \mathrm{~b}$ & $0.7 \mathrm{c}$ & $0.8 \mathrm{c}$ \\
\hline
\end{tabular}

$\mathrm{x}$ Tested isolates composition: VCG1: 3, 2, and 1 from France, The Netherlands, and Israel, respectively; VCG2: 6, 6, and 3 from France, The Netherlands, and Israel, respectively; VCG3: 2 and 4 from The Netherlands and Israel, respectively; VCG4: 5 and 2 from The Netherlands and Israel, respectively.

y Stem colonization; the number of CFU in the plants.

z Sclerotia density was visually evaluated on a scale of 0 to 3 , where $0=$ no sclerotia, $1=$ less than $25 \%$ of plant tissue covered with sclerotia, $2=25$ to $50 \%$ cover, and $3=$ more than $50 \%$ cover. One-way analysis of variance was carried out at $P=0.05$. Means were separated by Tukey-Kramer multiple range tests. Different letters within a column indicate significant differences. 


\section{DISCUSSION}

The present study demonstrates for the first time the occurrence of VCG diversity within $C$. coccodes. We identified four multimember VCGs among 110 isolates of $C$. coccodes recovered from potato. Isolates from VCG1 and VCG2 were recovered from all three countries (Israel, The Netherlands, and France), whereas VCG3 and VCG4 were not recovered from the sample from France. Thirty isolates, derived from all three countries, were incompatible with the selected testers and could not be assigned to any of the four multimember VCGs.

VCG analysis based on generating Nit mutants on WAC medium (18) resulted in recovery of at least one Nit mutant for each isolate (Table 2). Therefore, WAC medium was found suitable for generation of Nit mutants in $C$. coccodes. In the present study, we identified two phenotypic classes of Nit mutants among $502 \mathrm{mu}-$ tants; $84.3 \%$ of these isolates were identified as nit1/nit3 and $15.7 \%$ as NitM. Similar recovery frequencies of nit1 and NitM classes also were found for Verticillium lecanii (17) and V. dahliae (18) on WAC medium, and for C. destructivum, C. gloesporioides, and C. fragariae on potato dextrose agar medium amended with chlorate (4). Thus, it appears that, in $C$. coccodes, the genetic control of nitrate assimilation in particular, and nitrogen catabolism in general, are similar to those of other species of Colletotrichum, and other genera, such as Aspergillus, Neurospora, Fusarium, and Verticillium, whose VCGs have been previously studied.

Complementation levels within each VCG (Table 1) indicated a large diversity of isolate responses to different tester isolates, particularly within VCG2, where more testers were needed in order to assign isolates. These findings are similar to the findings of Joaquim and Rowe (12), in which different strengths of vegetative compatibility were found among strains of $V$. dahliae towards tester strains in some VCGs. In such cases, the number of testers that will need to be used depends on the degree of reaction heterogeneity produced among members in each VCG. Therefore, the variability in heterokaryon formation complicates the VCG analysis of $C$. coccodes because of the need for more tester isolates for each VCG. It also suggests that there may be an underlying genetic diversity in the VCG, for which molecular markers will be needed for further testing.

The finding that Israeli isolates shared VCGs with European isolates is not surprising, because there have been regular exchanges of potato seed tubers or table potatoes between Europe and Israel. The assignment of isolates from French sources only to VCG1 and VCG2 (Table 3) may indicate a possible adaptation of these VCGs to climate conditions in specific areas where seed tubers are produced, or that there are regional differences in VCG composition of populations. Another possible reason that not all groups were recovered from all three countries could be that sampling error limited collection of some rarer population components. It is also interesting to note that the smallest sample (France, $n=26$ ) is also the sample where two VCGs are missing. Finding the same VCGs in different countries could be due to founder effect but it could be also due to other reasons, such as gene flow, selection, or limited number of polymorphic vegetative incompatibility genes.

Of the tested isolates used in this study, $27 \%$ could not be assigned to any of the four multimember VCGs, which indicates that numerous single-member VCGs exist. Without molecular marker genotyping, more extensive pathogenicity testing, or considerably larger sampling, VCGs alone do not suffice to completely characterize these populations. The $27 \%$ unique VCGs could be the result of numerous factors including, but not limited to, cryptic sexual or asexual recombination or the presence of a large pool of more weakly pathogenic $C$. coccodes. For example, high VCG diversity and molecular diversity have been detected in nonpathogenically specialized populations of $F$. oxysporum $(8,21)$. There is, as yet, no clear answer from the existing data.
In order to test if there is a correlation between VCG and pathotype in $C$. coccodes, we compared pathogenicity of representative isolates of $C$. coccodes from the four multimember VCGs on susceptible potato cultivars. VCG3 isolates were observed as the most aggressive and had the highest stem colonization levels and sclerotia density on roots and crown. Isolates of VCG1 and VCG2 were moderately aggressive, and VCG4 isolates were the least aggressive. These results are in agreement with results from previous studies on $V$. dahliae, which have demonstrated some correlations between VCGs and virulence on certain hosts $(2,12,13)$. In North America, VCG4A isolates were more aggressive on potato than VCG4B, 4AB, and 2B isolates $(13,26)$. Moreover, VCG4A isolates interacted synergistically with the root lesion nematode Pratylenchus penetrans, causing reduced tuber yield (3). In Israel, VCG4B isolates were the most aggressive to potato, and VCG2A isolates were the most aggressive to tomato (28). VCG1 isolates were cotton-defoliating pathotypes, but nonpathogenic on tomato (14). Similarly, the correlations between VCG and pathogenicity may be significant in $C$. coccodes. Differences in aggressiveness of VCGs may have practical importance, especially for potato crops in which $C$. coccodes has become an important pathogen. Soil and seed tuber assays for $C$. coccodes estimate pathogen levels, but do not differentiate between VCGs. If VCGs differ in aggressiveness, the pathogen present in soil or in seed tubers does not necessarily indicate the potential for damage. Data on the VCG distribution of detected populations, and of the relative aggressiveness of each VCG, would enable a more accurate evaluation of potential damage and the necessary control measures. Determination of potential aggressiveness to potato in $C$. coccodes populations is also important for accurate selection of isolates when screening resistant and tolerant lines in breeding programs.

In conclusion, four multimember VCGs observed within the species $C$. coccodes indicate population differentiation and genetic diversity within subpopulations. The aggressiveness of VCG3 isolates to potato was the highest. We have defined a set of 12 tester strains for conducting VCG complementation tests that can now be used to characterize and begin to compare populations of $C$. coccodes worldwide. However, in order to improve understanding of the structure of populations, additional isolates from other potato-growing regions should be tested for VCGs. Moreover, isolates from other locations in addition to Europe and Israel must be included in order to establish international tester strains.

\section{ACKNOWLEDGMENTS}

Contribution from Agricultural Research Organization, Institute of Plant Protection, Bet Dagan, Israel, 514/01. We thank J. Joseph for editing the manuscript.

\section{LITERATURE CITED}

1. Andrivon, D., Ramage, K., Guerin, C., Lucas, J. M., and Jouan, B. 1997. Distribution and fungicide sensitivity of Colletotrichum coccodes in French potato-producing areas. Plant Pathol. 46:722-728.

2. Bhat, R. G., and Subbarao, K. V. 1999. Host range specificity in Verticillium dahliae. Phytopathology 89:1218-1225.

3. Botseas, D. D., and Rowe, R. C. 1994. Development of potato early dying in response to infection by two pathotypes of Verticillium dahliae and co-infection by Pratylenchus penetrans. Phytopathology 84:275282.

4. Brooker, N. L., Leslie, J. F., and Dickman, M. B. 1991. Nitrate nonutilizing mutants of Colletotrichum and their use in studies of vegetative compatibility and genetic relatedness. Phytopathology 81:672-677.

5. Byrne, J. M., Hausbeck, M. K., Meloche, C., and Jarosz, A. M. 1998. Influence of dew period and temperature on foliar infection of greenhouse-grown tomato by Colletotrichum coccodes. Plant Dis. 82:639-641.

6. Chesters, C. G. C., and Hornby, D. 1965. Studies on Colletotrichum coccodes. I. The taxonomic significance of variation in isolates from tomato roots. Trans. Br. Mycol. Soc. 48:573-581.

7. Correll, J. C., Gordon, T. R., and McCain, A. H. 1988. Vegetative compatibility and pathogenicity of Verticillium albo-atrum. Phytopathology 
78:1017-1021

8. Correll, J. C., Puhalla, J. E., and Schneider, R. W. 1986. Identification of Fusarium oxysporum f. sp. apii on the basis of colony size, virulence, and vegetative compatibility. Phytopathology 76:396-400.

9. Denner, F. D. N., Millard, C., Geldenhuys, A., and Wehner, F. C. 1997. Treatment of seed potatoes with prochloraz for simultaneous control of silver scurf and black dot on daughter tubers. Potato Res. 40:221-227.

10. Denner, F. D. N., Millard, C., and Wehner, F. C. 1998. The effect of seedand soilborne inoculum of Colletotrichum coccodes on the incidence of black dot on potatoes. Potato Res. 41:51-56.

11. Hong, J. K., and Hwang, B. K. 1998. Influence of inoculum density, wetness duration, plant age, inoculation method, and cultivar resistance on infection of pepper plants by Colletotrichum coccodes. Plant Dis. 82:1079-1083.

12. Joaquim, R. R., and Rowe, R. C. 1990. Reassessment of vegetative compatibility relationships among strains of Verticillium dahliae using nitrate non-utilizing mutant. Phytopathology 80:1160-1166.

13. Joaquim, T. R., and Rowe, R. C. 1991. Vegetative compatibility and virulence of strains of Verticillium dahliae from soil and potato plants. Phytopathology 81:552-558.

14. Katan, T. 2000. Vegetative compatibility in populations of VerticilliumAn overview. Pages 69-86 in: Advances in Verticillium, Research and Disease Management. E. C. Tjamos, R. C. Rowe, J. B. Heal, and D. R. Fravel, eds. The American Phytopathological Society, St. Paul, MN.

15. Katan, T., and Katan, J. 1988. Vegetative compatibility grouping of Fusarium oxysporum f. sp. vasinfectum from tissue and rhizosphere of cotton plants. Phytopathology 78:852-855.

16. Katan, T., Zamir, D., Sarfatti, M., and Katan, J. 1991. Vegetative compatibility groups and subgroups in Fusarium oxysporum f. sp. radicislycopersici. Phytopathology 81:255-262.

17. Korolev, N., and Gindin, G. 1999. Vegetative compatibility in the entomopathogen Verticillium lecanii. Mycol. Res. 103:833-840.

18. Korolev, N., and Katan, T. 1997. Improved medium for selecting nitrate non-utilizing (nit) mutants of Verticillium dahlia. Phytopathology 87:1067-1070

19. Korolev, N., Katan, J., and Katan, T. 2000. Vegetative compatibility groups of Verticillium dahlia in Israel: Their distribution and association with pathogenicity. Phytopathology 90:529-536.

20. Leslie, F. J. 1993. Fungal vegetative compatibility. Annu. Rev. Phytopathol. 31:127-150.

21. Marlatt, M. L., Correll, J. C., Kaufmann, P., and Cooper, P. E. 1996. Two genetically distinct populations of Fusarium oxysporum f. sp. lycopersici race 3 in the United States. Plant Dis. 80:1336-1342.

22. Puhalla, J. E. 1979. Classification of isolates of Verticillium dahlia based on heterokaryon incompatibility. Phytopathology 69:1186-1189.

23. Puhalla, J. E. 1985. Classification of strains of Fusarium oxysporum on the basis of vegetative compatibility. Can. J. Bot. 63:179-183.

24. Puhalla, J. E., and Hummel, M. 1983. Vegetative compatibility groups within Verticillium dahlia. Phytopathology 73:1305-1308.

25. Read, P. J., and Hide, G. A. 1988. Effect of inoculum sources and irrigation on black dot (Colletotrichum coccodes (Wallr.) Hughes) and its development during storage. Potato Res. 31:493-500.

26. Strausbaugh, C. A. 1993. Assessment of vegetative compatibility and virulence of Verticillium dahliae isolates from Idaho potatoes and tester strains. Genetics 83:1253-1258.

27. Tsror (Lahkim), L., Erlich, O., and Hazanovsky, M. 1999. Effect of Colletotrichum coccodes on potato yield, tuber quality, and stem colonization during spring and autumn. Plant Dis. 83:561-565.

28. Tsror (Lahkim), L., Hazanovsky, M., Mordechi-Leviush, S., and Sivan, S. 2001. Aggressiveness of Verticillium dahlia isolates from different vegetative compatibility groups to potato and tomato. Plant Pathol. 50:477-482.

29. Tsror (Lahkim), L., and Johnson, D. A. 2000. Colletotrichum coccodes on potato. Pages 362-373 in: Colletotrichum-Host Specificity, Pathology and Host-Pathogen Interaction. D. Prusky, S. Freeman, and M. B. Dickman, eds. The American Phytopathological Society, St. Paul, MN. 